\title{
AN ASSESSMENT OF THE LIFETIME OF FARADAY SHIELD ELEMENTS*
}

\author{
J. B. O. Caughman, II, and D. N. Rueic \\ Univeraity of Illinois, Urbana, Illinais 61801 \\ D. J. Hoffman, R. A. Langley, M. B. Lewis, and P. M. Ryan \\ Oak Ridge National Laboratory, Oak Ridge, Tennessee 97891-8071
}

\begin{abstract}
The interaction of plasma with of fields from an ion cyclotron range of frequencies (ICRF) antenna has been studied to eatimate the amount of Faraday shield erosion expected in normal ICRF heating (ICRH) operation. Plasm parametera and ion energies have been measured in the near field of an antenina and used in a model to eatimate the erosion rate of the Faraday shield surface. Experiments were conducted on the RF Teat Facility (RFTF), a magnetic mirror device at Oak Ridge National Laboratory (ORNL), using a singlestrap resonant loop antenna with a two-tier Faraday shield. The outer tier, facing the plasma, was layered with graphite tiles. The antenna was operated at currents and voltages ( $\sim 500 \mathrm{~A}, \sim 20 \mathrm{kV}$ at $25 \mathrm{~kW})$ within $50 \%$ of those expected in tokamaks. The timevarying floating potential was measured with a capacitively coupled probe, and the time-averaged floating potential, electron temperature, and electron density were measured with a Langmuir probe. Both prober were scanned in front of the antenna. Ion energies were measured with a gridded energy analyser located below the antenna, and amples of silicon were placed on the Faraday shield surface to estimste the incident ion energy. The capacitive probe measurements show that the rf floating potential follows the magnetic field pattern of the antenna, indicating that the electromagnetic fields are responsible for the potential formation. Electron temperatures increase with $\mathrm{f} f$ power and can reach values $\geq 60 \mathrm{eV}$ for an $\mathrm{rf}$ power of $\sim 25 \mathrm{~kW}$. Incident ion energies $\geq 300 \mathrm{eV}$ have been measured for the same power levei. Plasma parameters and ion energies have been correlated with the antenna current and used in a computational model of the plasma sheath to predict the amount of erosion expected from the Faraday shield elements exposed to plesma. Predictions of light ion sputtering of candidate Faraday shield materials are presented.
\end{abstract}

CONF-891007--83
DE90 002714

\section{INTRODUCTION}

Experiments on several confinement devices have shown an increase in the impurity concentration in the

Recearch supported by the Magnetic Funion Energy Technology Fellowship program, adminiatered by Oak Ridge Ausciated Univeraities for the U.S. Department of Energy, and the Office of Fusion Energy, U.S. Department of Energy, under contract DE-AC05-84OR21400 and subcontract $19 X-S B 359 \mathrm{~V}$ with Mertin Meriette Energy Syateme, Inc. 
plasma during ICRH [1-T]. Specifically, the Faraday shield of the antenns has been identified as a local impurity source $[8,9]$. The increase in the impurity release from the antenns will decrease its lifetime because of the erosion of its plasma facing components. Therefore, the processes taking place at the antenna that cause the increase in the impurity generation must be identified. One area that needs to be acdressed in understanding the impurity generation is the role of the plasma sheath that forms on the material boundaries in contact with the plasma. Ions are accelerated through the sheath and hit the antenna, causing material erosion. The magnitude and form of the plasma potential in front of the sntenna must be known to determine the effect of this potential on the energy of the ions hitting the shield. The effect of the electron temperature and the if fields on the potential formation in front of the antenns must be determined.

Plasme parameters and ion energies have been measured near an ICRF antenna Faraday shield in an experiment conducted on the RFTF at ORNL [10]. The antenna used was a single-strep resonant loop antenna with a grounded two-tier Faraday shield, shown in Fig. 1. The antenno was operated at $42 \mathrm{MHs}$, and the If power was varied up to $60 \mathrm{~kW}$. The RFTF plasma was initiated and sustained by electron cyclotron heating (ECH) using \& 10.6-GHe kystron with an output power of $\sim 17 \mathrm{~kW}$. Typically, the planme discharge was pulsed for $200 \mathrm{~ms}$, and the antenna was pulsed for 150 ms during the plasme pulse. Hydrozen was used as the operating gas for most of the experiments at pressures ranging from $1 \times 10^{-4}$ to $4 \times 10^{-4}$ Torr. The electron temperature at the antenna was $5-10 \mathrm{eV}$, and the electron density was $\sim 5 \times 10^{10} \mathrm{~cm}^{-3}$. The magnetic field at the antenna was $\sim 2$ kG and in a direction parallel to the Faraday shield elements.

\section{EXPERIMENT}

The time-varying flosting potential was measured with a capacitively coupled probe that was scanned in front of the antenna, parallel to the current strap, from $7 \mathrm{~cm}$ below the shorted end of the current strap to $22 \mathrm{~cm}$ above the shorted end. The probe was calibrated at the rf frequency (42 M I ) $[11]$ : - A Tangmuir probe was scanned in the same area the cor pacitive probe to mesure the time-averaged flosting potential, electron temperature, and electron density. Both probe tips were $\sim 1 \mathrm{~cm}$ from the surface of the Faraday shield. The responce of the Langmuir probe in the presence of $x f$ fields was considered in the analysis of the probe characteristica. The Langmuir probe was terminated on a small de and $f($ load and thus 
measured the time-averaged current as a function of applied bian voltage. The electron temperature was taken from the lower portion of the $I_{e}$ vo $V$ curve to avoid problems associated with response of a Langmuir probe to an if plasma [12]. The electron density was calculated by measuring the probe current well into ion saturation and then corrected with the LaFramboise method [13]. The time-averaged floating potential was taken from the time-averaged current measurement and then corrected for self-bias due to $\mathrm{f}$ effects [14]. The time-averaged plama potential was eatimated from the $\ln \left(I_{e}\right)$ va $V_{\text {bias }}$ curve [15].

A gridded energy analyser, located $\sim 4 \mathrm{~cm}$ below the antenna and facing the planme, measured the ditribution of ion energies incident on a grounded surface. Since the magnetic field was parallel to the surface and to the biasing grids of the analyzer, the analyzer was thin ( $\leq 1 \mathrm{~mm}$ thick) so that the ion energies perpendicular to the magnetic field could be measured. The outside of the analyrer and its entrance grid were grounded, so that the anergy of the ions accelerated through the sheath that formed on a grounded surface was measured.

Samples of silicon were placed on and near the antenna to estimste the energy of the ions accelerated through the plasma sheaths that formed on surfaces. Some samples were placed in the ame locstion as the energy analyser, and some were placed on the Faradsy shield surface at a locution $\sim \mathbf{1 6} \mathrm{cm}$ from the shorted end of the antenna. Some of the samples were exposed only to ECH plasmas; some were exposed to ECH plasmas with if power radiating from the antenna. The samples were exposed to a near-saturation fluence $(\sim 5 \times$ $10^{17} \mathrm{D} / \mathrm{cm}^{-3}$ ) from a deuterium plasms. The incident fluence was eatimated by measuring the current to the samples. The amount of deuterium retained in the samples after exposure to asturation levels of a deuterium ion fluence is related to the energy of the incident ions [16] and was determined by using $\mathrm{D}\left({ }^{3} \mathrm{He}, \mathrm{p}\right)^{4} \mathrm{He}$ nuclear reaction analysis.

\section{RESULTS}

The capacitive probe results indicate that the floating potential near the antenns oscitlates at the if frequency and can reach values of up to $300 \mathrm{~V}$ p-p for an antenna current of $\sim 400$ A. The if floating potential, normalized by the sntenns current, is shown in Fig. 2 for gas pressures of $(1-3) \times 10^{-4}$ Torr and for $f f$ powers ranging from 12 to $55 \mathrm{~kW}$. The potentials are all measured $\sim 1 \mathrm{~cm}$ in front of the Faraday shield and are referenced from the shorted end of the antenne. Since the rf fieid strength is proportiond to the antenne current, 
the potentials were normalized by the antenna current to look for any dependence on the if field strength. The waveform of the potential was sinusoidal for all cases. For each data set at the same pressure, the data show the trend of being fairly level in the middle of the current strap and decreasing slightly towards the ends of the strap. These potentials follow the magnetic field pattern of the antenna instead of the voltage distribution on the current strap, indicating that the potential formation was due to the electromagnetic fields and not the electrontatic fields.

The difference between the normalized potentials for the $1 \times 10^{-4}$ Torr experiment and the $(2-3) \times 10^{-1}$ Torr experiments may be due to the capacitance of the If shesth at the probe tip. The sheath capacitance acts as a series capacitor between the probe tip and the plasma and decreases the coupled aignal to the probe tip. The sheath capacitance will increase as the electron density increases because the sheath thickness is thinner, and the coupled voltage to the probe tip will increase. The plasma densities were lower for the lower gas pressures, typically $(1-3) \times 10^{10} \mathrm{~cm}^{-3}$ for the $1 \times$ $10^{-1}$ Torr experiment, and increased to $(8-16) \times 10^{10}$ $\mathrm{cm}^{-3}$ for the $4 \times 10^{-4}$ Torr experiment.

The electron temperature and the time-averaged plasms potential in front of the antenna are shown in Fig. 3 for a gas fill pressure of $2 \times 10^{-4}$ Torr. Also shown are date from below the antenna, close to the energy analyzer. The electron temperature and the plaoms potential clearly increase with if power and antenns current. Electron temperatures for an ECH plasma without if power from the antenna were 5-10 $\mathrm{eV}$ (curve 1) and increased to $54-60 \mathrm{eV}$ for an ECH plasms with an applied if pover of $\sim 26 \mathrm{~kW}$ and an antenna current of $\sim 390 A_{i}$ the average plasma potential for an ECH plasma without if power from the antenna was 7-12 V (curve 1) and increased to 180-230 V for these $r$ conditions. Both the electron temperature and the average plams potential were fairly constant in front of the antenna, indicating an electromagnetic field dependence.

There was no clear dependence of the electron temperatcre or the plasma potential on the local electron density. Without if power from the antenna, the plasma densities were $(3-5) \times 10^{10} \mathrm{~cm}^{-3}$ in front of the anrenna and about $7 \times 10^{10} \mathrm{~cm}^{-3}$ below it. The electron density in front of the antenns decreased $\sim 50 \%$ at lower if power and 25-50\% at higher if power. The density below the antenna decreased $\sim 25 \%$ for the lower if power case and incressed $\sim 50 \%$ with higher if power. Even though the density increased, the electron temperature and the average plasma potential followed a scaling similar to that of the parameters in front of the 
sntenns. Experiments at $4 \times 10^{-1}$ Torr showed that the temperature and potential acaled with the antenna current in the same way, even though the density in front of the antenns increased 100 to $150 \%$ for an if power of $\sim 11.2 \mathrm{~kW}$.

Energies for ions hitting a grounded surface also increased with rf power and antenna current. The perpendicular ion energy distribution measured with the energy analyzer is shown in Fig. 4 for the three sets of plasms and antenna conditions. The fine structure of the distributions is not meaningful because of the uncertainty involved in the messurement. The distributions were normalized so that the integral over the energy was one. The ion energy distributions were generally peaked near the tirne-averaged plasma potential for all the experiments. Energy distributions were peaked at s-10 eV for the experiments without if and increased with if power. lons with energies above $300 \mathrm{eV}$ were measured for experiments with on rf power of $\sim 20 \mathrm{~kW}$ and an antenna curient of $\sim 400 \mathrm{~A}$. The distributions were clearly shifted to higher energies with the higher if power and antenne curr,sst. The magnitude of the energy shift follows roughly the same scaling as the electron temperature increase, indicating that the electrons caused an increase in the sheath potential, thereby increasing the energy of the irons that hit the surface.

The surface probe reasils for the experiments are shown in Fig. 5. Sorse of the samples were negatively biased and exposed to deuteriun plasmas without if power from the antenna. The negative bias allowed the ions to have an equivalent energy of the plasma potential $(\sim 20 \mathrm{~V})$ plus the magnitude of the applied bias voltage. The amounts of deuterium trapped in the biased samples for various incident fluences are shown as the solid points in the figure. The amount of trapped deuterium was within the range of previous experimental results for monoenergetic deuterium incident on silicon [16], shown as dotted lines in the figure.

The samples exposed to a plasma with if power from the antenna had more trapped deuterium than the sample with the $-250-\mathrm{V}$ bias, indicating an increase in the ion energy hitting the surface. One sample (grounded) was at the same location as the biased samples ( $\sim 4$ cm below the antenna), and the other sample was in the middle of the Faraday shield of the antenna, $\sim 16$ $\mathrm{cm}$ from the shorted end of the current strap. The rf power was $\sim 22 \mathrm{~kW}$, and the antenna current was $\sim 269$ A. Although the amounts of trapped deuterium in these samples were greater than in the $-250-\mathrm{V}$ bias sample (ion energy $\sim 270 \mathrm{eV}$ ), it does not mean that all the ions had an energy greater than $270 \mathrm{eV}$. The ion energy distribution will affect how much is retained, so well as the impact angle [17]. Higher energy ions from 
the distribution can cause the trapped amounts to increase [16]. Since the exact distribution is not known, these results should be interpreted as indicating that, for these experimental conditions, some of the ions hitting the Faraday shield had an energy above $270 \mathrm{eV}$.

\section{DISCUSSION}

The electron temperature, plasma potential, and impacting ion energy in the region in front of the antenna clearly increase with antenna current and nearfield strength. The increase in the ion energies messured with the energy analyzer is consistent with an increased sheath potenticl reaulting from in increase in the electron temperature. These large potentials, coupled with the acceleration of the ions through the resulting shesth, will cause an increase in the amount of erosion from the Faraday shield because of the increase in the energy of the ions hitting the shield surface.

A computational model of the sheath has been developed to estimate the energy of the ions incident on the Faraday shield surface [15]. Inputs to the model include measured data, such as the magnitude of the time-varying plasma potential, the time-averaged plasma potential, and the electron temperature. Other inputs are the static magnetic field strength, the electron density, and the ion temperature. As an example of the model, the measured data from the RFTF experiment (Figs. 2-4) were scaled up with antenns current to estimate the conditions that may exist directly in front of an antenna in a large tokamak, such as TFTR or JET. For an antenna current of $800 \mathrm{~A}$, the inputs to the model for the tokamak-like conditions were an average plasma potential of $480 \mathrm{~V}$, a time-varying plasms potential of $130 \mathrm{~V}$, and an electron temperature of 110 $\mathrm{eV}$. The electron density was assumed to be $1 \times 10^{12}$ $\mathrm{cm}^{-3}$, the magnetic field was $3.6 \mathrm{~T}$, the ion semperature was $37 \mathrm{eV}$, the of frequency wus $47 \mathrm{MHs}$, and the plasma was asoumed to be deuterium. The results of the model for these conditions are whown in Fig. 6. The fine structure is due to numerical uncertainties in the calculation. The peak in the ion energy diatribution occurs near the peak in the plasma potential. This population of higher energy ions will increase the effective sputtering yield of the ions incident on the Faraday shield surface. The sputtering yield is slso affected by the ion impact angle. The model results show that the average angle at which the ions will hit the shield is $39^{\circ}$.

The decrease in the lifetime of the Faraday shield due to physical sputtering can be calculated from the results of the computational model for light ion aputtering of various Faraday shield materials. The calculated 
ion energy distribution at the Foraday shield surface for the tokamak-like conditions described above was used in an analytical expression for calculating the sputtering yield for deuterium sputtering of beryllium, copper, nickel, titanium carbide, and graphite [18]. This analytical expression is typically accurate to within a factor of two. The angular dependence on the sputtering yield was approximated as having a $1 / \cos (\theta)$ distribution for ion energies greater than $200 \mathrm{eV}$. The results of this calculation are shown in Table 1 . For comparison, the ion energy distribution at the surface without rf effects was approximated as being a half-Maxwellian $\left(T_{i}=T_{e}\right)$ shifted by the sheath potential $\left(\sim 3 T_{e}\right)$. No angular dependence was asaumed. Reaults from the analytical sputtering formula for this distribution for electron temperatures of $20 \mathrm{eV}$ and $10 \mathrm{eV}$ are also shown in Table I. The sputtering yields for the rf conditions (Fig. 6) are higher than those for the non-rf conditions. Compared to the $20-\mathrm{eV}$ electron temperature calculation, the yield increases ranged from a factor of 1.7 for deuterium sputtering of beryllium up to a factor of 8.5 for deuterium sputtering of $\mathrm{TiC}$.

The erosion rate of the Faraday shield has been calculated from the sputtering yields shown in Table I. The erosion rate is given by the product of the incident ion flux, the sputtering yield, and the number density of the Faraday abield material. The number density was calculated as the mass density multiplied by $6.023 \times 10^{23}$ and divided by the atomic/molecular mass [19]. The erosion rates are also shown in Table I. These results were calculated for an incident flux of $1 \times 10^{17}$ ions $/ \mathrm{cm}^{2} \cdot \mathrm{s}$. The erosion rates are about the same for the deuterium sputtering of beryllium, titanium carbide, and graphite; they are higher for copper and nickl. At this incident flux, the plasma-facing antenns components in a tokamak run for 30-s pulses would erode $\sim 1 \mathrm{~mm}$ after $\sim 108,000$ pulses (for beryllium). This calculation does not include the effects of self-sputtering. Sputtering yields for the rf conditions would increase by more than an order of magnitude for self-sputtering, also increasing the erosion rate.

\section{CONCLUSIONS}

Experiments have shown that large plasma potentials exist in front of an ICRF antenna. Electron temperatures, plasma potensials, and ion energies clearly increase with antenna current and generally follow the near-field magnetic field pattern of the antenna, indicating that the increases in potential and temperature are due to the electromagnetic field and not the electroatatic field. The time-averaged plasma potential follows 
the same scaling as the electron temperature, indicating that the increase in sheath potential is due to an increase in the electron teraperature. This increased sheath potential causes an increase in the energy of the ions hitting the plasan-facing components of the antenna. Calculations of the distribution of ion energies at a grounded surface show that the ions will hit the surface with a spread in energies that is peaked near the maximum plasma potential for tokamak-like conditions. Sputtering yields and erosion rates will increase for these conditions, limiting the lifetime of the plasmafacing components of the antenna.

\section{REFERENCES}

[1] K. H. Behringer et al., in Proc. 19th European Conf. Controlled Fusion and Plasma Hating, Schliersee, 1986 , p. 176.

[2] J. Tachon, in Physics of Plasma-Wall Interactions in Controlled Funion, eds. D. E. Post and R. Behriach. New York: Plenum, 1986, p. 1005.

[3] G. Janeschitz et al., in Proc. 19th European Conf. Controlled Fusion and Plasma Heating, Schliersee, 1986, p. 407.

[4] B. Schweer et al., ibid., p. 399.

[5] A. deChambrier et al., J. Nucl. Mater., vols. 128 \& 129 , p. 310, 1984.

[6] H. Ogawa et al., J. Nucl. Mater., vols. 128 \& 129, p. 298, 1984.

[7] H. L. Manning et el., Nucl. Funion, vol. 26, p. 1665, 1986.

[8] M. Buržs et al., Plasma Phys. Controlled Fusion, vol. 30, p. 149, 1988.

[9] J.-M. Noterdaeme et al., in Proc. 14th European Conf. Controlled Fusion and Plasma Heating, Madrid, 1987, p. 678.

[10] W. L. Gardner et al., Bull. Am. Phys. Soc., vol. 30, p. $1590,1985$.

[11] J. B. O. Caughman, II, D. N. Ruric, and D. J. Hoffman, J. Vac. Sci. Technol. A, vol. 7, p. 1092, 1989.

[12] N. Hershkowitz, M. H. Cho, C. H. Nam, and T. Intrator, Plasma Chem. Planma Proceas., vol. 8, p. 35, 1988.

[13] P. M. Chung, L. Talbot, and K. J. Touryan, Electric Probes in Stationary and Flowing Plasmas: Theory and Application. New York: Springer-Verlag, Ig75.

[14] A. Boschi and F. Magiatrelli, Nuovo Cimento, vol. 29 , p. $487,1963$.

[15] J. B. O. Caughman, II, Ph.D. theris, University of Illinois at Urbane-Champaign, October 1989.

[16] G. Staudenmaier et al., J. Nucl. Mater., vol. 84, p. $149,1979$. 
[17] S. A. Cohen and G. M. McCracken, J. Nucl. Mater., vol. 84, p. 157,1979 .

[18] J. Bohdansky, p. 61 in Data Compendium for Plasma-Surface Interactions, Nucl. Fusion, Special Issue, 1984.

[19] CRC Handbook of Chemistry and Physics, 59th ed. West Palm Beach: CRC Press, 1978.

\section{FIGURE CAPTIONS}

Fig. 1. Front and sectional views of the resonant loop antenna, showing the position of the probes relative to the Faraday shield.

Fig. 2. The $\mathrm{rf}$ component of the floating potential normalized by the antenna current.

Fig. 3. (a) Electron temperature and (b) average plasma potential in front of the antenna for a gas pressure of $2 \times 10^{-1}$ Torr.

Fig. 4. Messured perpendicular ion energy distributions for a ges pressure of $2 \times 10^{-4}$ Torr.

Fig. 5. Nuclear reaction analysis data for the experiment. Also shown are the monoenergetic results (dotted lines [16]).

Fig. 6. Calculated (a) ion energy distribution and (b) ion angular distribution at the surface for tokamak-like conditions. Input parameters for the calculation were a de plasma potential of $480 \mathrm{~V}$, an rf potential of $130 \mathrm{~V}$, $n_{e}=1.0 \times 10^{12} \mathrm{~cm}^{-3}, T_{e}=110 \mathrm{eV}, T_{i}=37 \mathrm{eV}$, an if frequency of $47 \mathrm{MHz}$, and a magnetic field strength of $3.6 \mathrm{~T}$.

\section{DISCLAIMER}

This report was prepared as an account of work sponsored by an agency of the United States Government. Neither the United States Government nor any agency thereof, nor any of their employees, makes any warranty, express or implied, or assumes any legal liability or responsibility for the accuracy, completeness, or usefulness of any information, apparatus, product, or process disclosed, or represents that its use would not infringe privately owned rights. Reference herein to any specific commercial product, process, or service by trade name, trademark, manufacturer, or otherwise does not necessarily constitute or imply its endorsement, recommendation, or favoring by the United States Government or any agency thereof. The views and opinions of authors expressed herein do not necessarily state or reflect those of the United States Government or any agency thereof. 
Table I. Calculated aputtering yielda nnd pronion rntes for deuterium aputtering of Faraday shield materials

\begin{tabular}{|c|c|c|c|c|c|}
\hline & \multicolumn{5}{|c|}{ Material } \\
\hline & $\mathbf{B e}$ & $\mathrm{Cu}$ & $\mathrm{Ni}$ & $\mathrm{TiC}$ & Graphite \\
\hline \multicolumn{6}{|c|}{ Sputtering yield (atoms/ion) } \\
\hline $\begin{array}{l}\text { Conditions of Fig. } 6 \\
\text { No } \mathrm{rf}, T_{e}=20 \mathrm{eV} \\
\text { No } \mathrm{r}, T_{e}=10 \mathrm{eV}\end{array}$ & $\begin{array}{l}3.82 \times 10^{-3} \\
2.27 \times 10^{-2} \\
6.21 \times 10^{-3}\end{array}$ & $\begin{array}{l}1.06 \times 10^{-1} \\
7.94 \times 10^{-3} \\
3.99 \times 10^{-4}\end{array}$ & $\begin{array}{l}5.63 \times 10^{-2} \\
6.66 \times 10^{-3} \\
6.66 \times 10^{-4}\end{array}$ & $\begin{array}{l}1.91 \times 10^{-2} \\
2.25 \times 10^{-3} \\
2.05 \times 10^{-4}\end{array}$ & $\begin{array}{l}4.81 \times 10^{-2} \\
1.54 \times 10^{-2} \\
2.59 \times 10^{-3}\end{array}$ \\
\hline \multicolumn{6}{|l|}{ Erosion rate ${ }^{a}(\mathrm{~cm} / \mathrm{a})$} \\
\hline $\begin{array}{l}\text { Conditions of Fig. } 6 \\
\text { No rf, } T_{\mathrm{e}}=20 \mathrm{eV} \\
\text { No rf, } T_{\mathrm{e}}=10 \mathrm{eV}\end{array}$ & $\begin{array}{l}3.08 \times 10^{-8} \\
1.83 \times 10^{-8} \\
5.01 \times 10^{-0}\end{array}$ & $\begin{array}{l}1.25 \times 10^{-7} \\
9.35 \times 10^{-0} \\
4.02 \times 10^{-10}\end{array}$ & $\begin{array}{l}6.17 \times 10^{-8} \\
7.29 \times 10^{-0} \\
7.26 \times 10^{-10}\end{array}$ & $\begin{array}{l}3.85 \times 10^{-8} \\
4.53 \times 10^{-0} \\
1.71 \times 10^{-8}\end{array}$ & $\begin{array}{l}5.33 \times 10^{-0} \\
1.71 \times 10^{-0} \\
2.87 \times 10^{-9}\end{array}$ \\
\hline
\end{tabular}

a For a flux of $10^{17} \mathrm{D}^{+} / \mathrm{cm}^{2}$. 
OANL-DWG 80-3635A FED

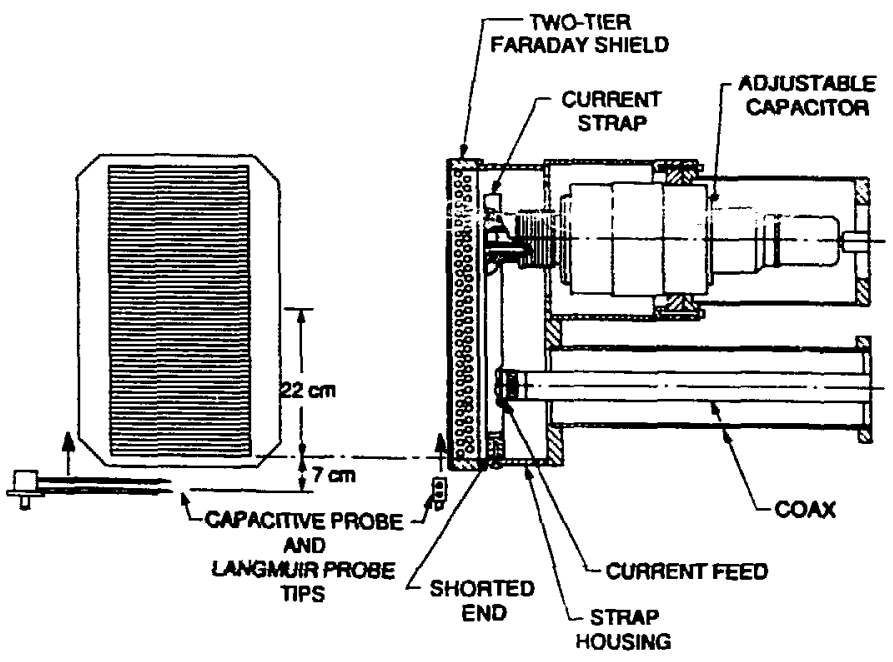




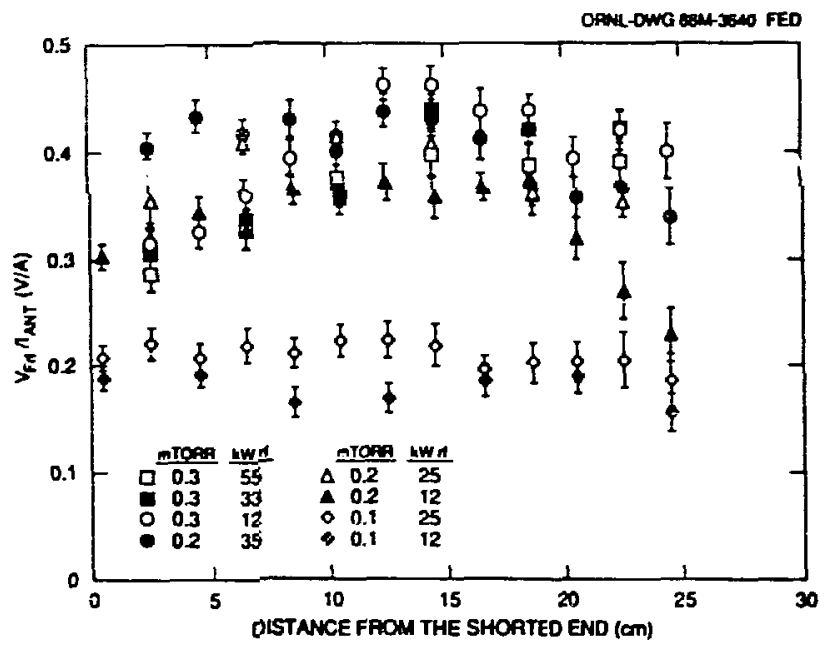




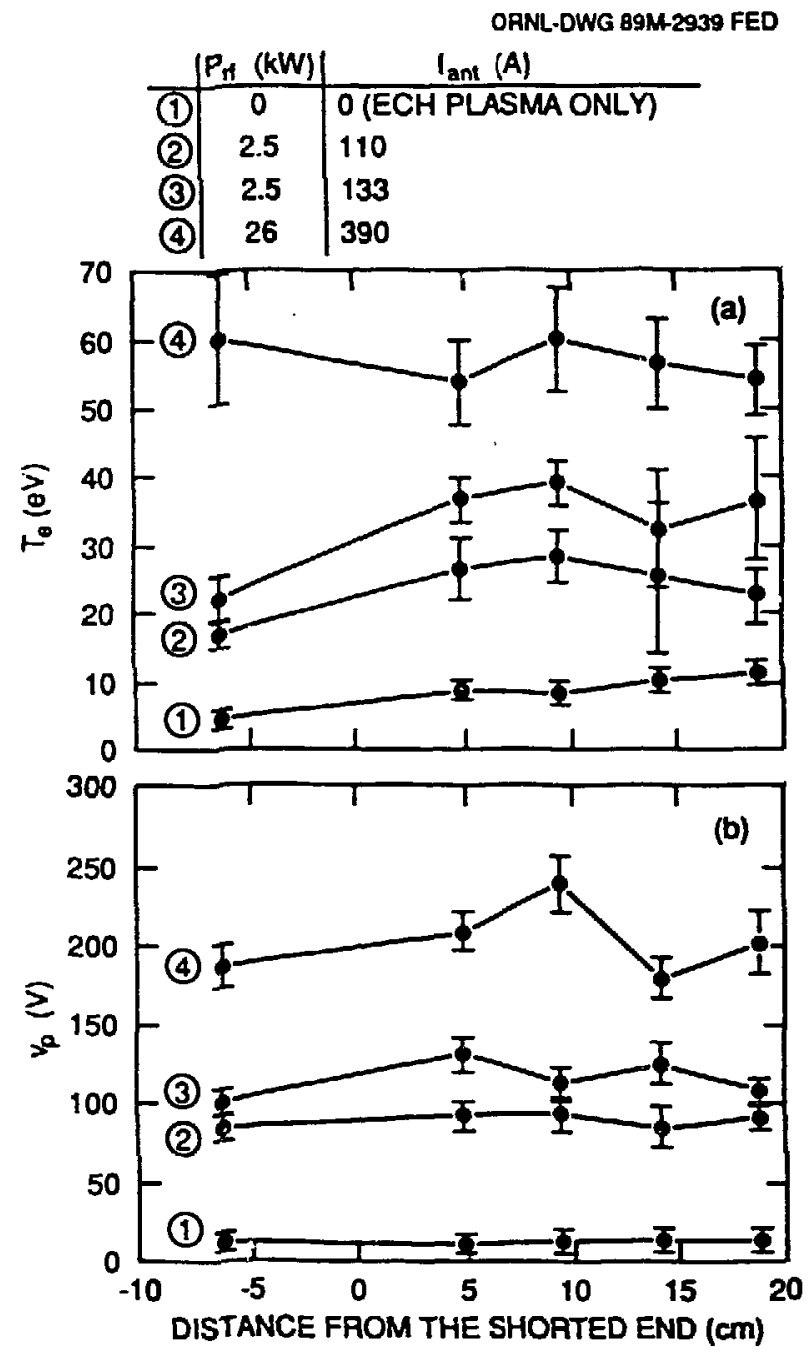




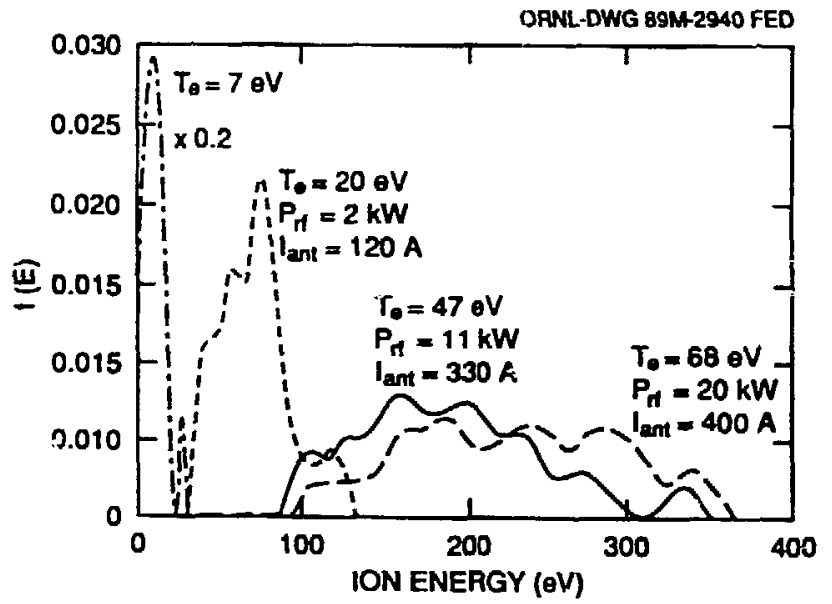




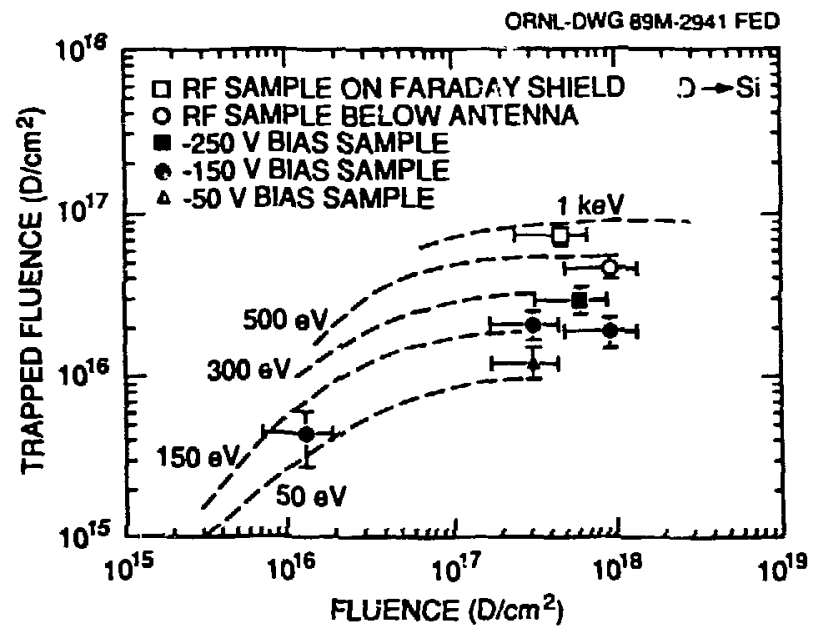



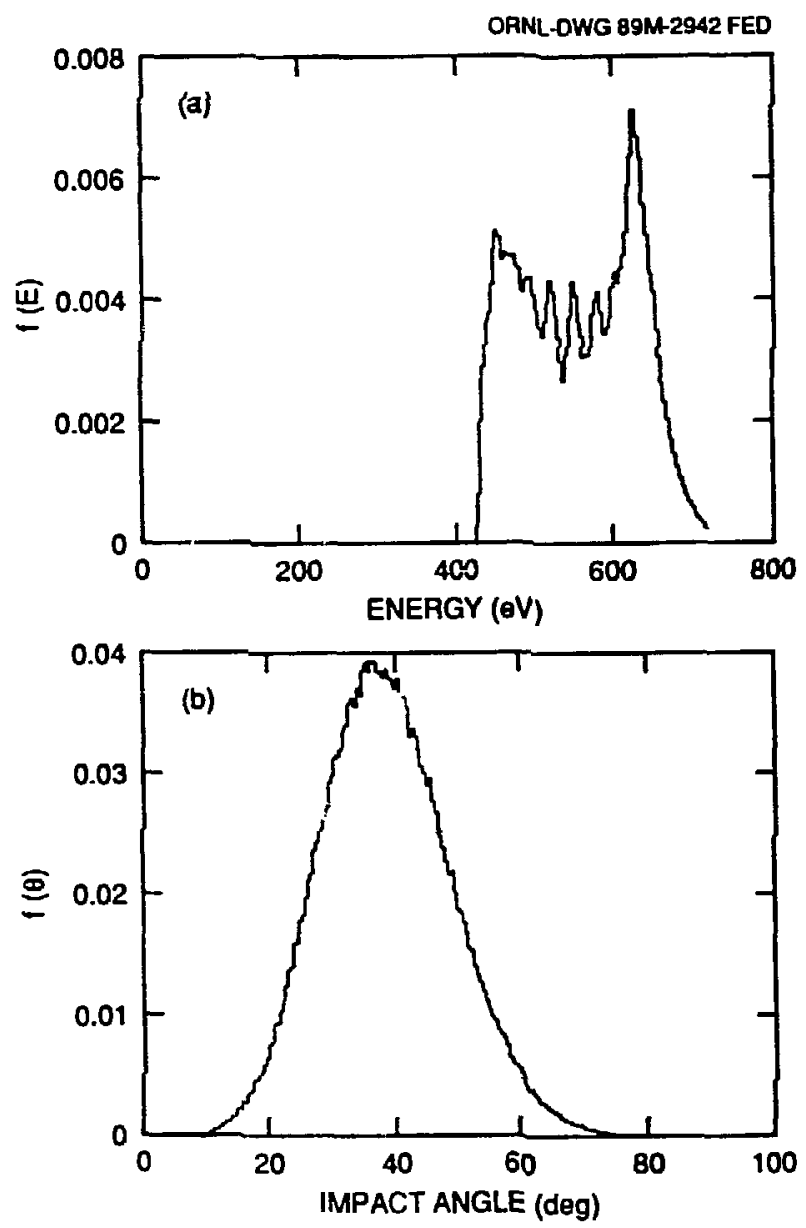